\title{
Perceptual Focus Effects in Choice
}

\author{
RYAN HAMILTON \\ JIEWEN HONG \\ ALEXANDER CHERNEV*
}

This article examines consumer choice as a function of the perceptual similarity of the options in the decision set. In particular, we examine a scenario in which a set of options is extended by adding alternatives that change its perceptual characteristics, increasing the salience of one of the options in the core set. In this context, we document that, contrary to normative predictions, perceptual focus can increase the choice share of one of the core options, even when the added alternatives are dominated by both options in the core set. We further show that the observed effect is a function of consumers' mode of information processing and is more pronounced in the context of intuitive (System 1) processing than analytic (System 2) processing.

\begin{abstract}
$\mathrm{C}$ onsumer decisions are often not based on well-defined preferences and are instead influenced by the characteristics of the choice context, such as the specific methods used to describe alternatives or the number of options under consideration (Bettman, Luce, and Payne 1998; Payne 1982; Simonson and Tversky 1992). One of the most robust demonstrations of the context-based nature of consumer preferences is the attraction effect. The attraction (or asymmetric dominance) effect refers to the empirical finding that adding an option that is dominated by only one alternative in the original set (i.e., asymmetrically dominated) can increase the preference for the dominating option (Huber, Payne, and Puto 1982).

Most research on context effects, including that on the attraction effect, has explored how context affects relatively deliberate analytic processes. For instance, Simonson (1989) found that an asymmetrically dominated option can simplify choice by providing a reason for choosing the dominating option. In the same vein, other research has shown that consumers may use the additional information provided by the asymmetrically dominated option to infer where their preferences fall relative to those of other consumers (Prelec, Wernerfelt, and Zettelmeyer 1997).
\end{abstract}

*Ryan Hamilton (r-hamilton@kellogg.northwestern.edu) and Jiewen Hong (j-hong@kellogg.northwestern.edu) are Ph.D. candidates, and Alexander Chernev is associate professor of marketing (ach@northwestern .edu), Kellogg School of Management, Northwestern University, 2001 Sheridan Road, Evanston, IL 60208. The authors thank the editors, the associate editor, and the three anonymous reviewers for their constructive comments.

John Deighton served as editor and Barbara Kahn served as associate editor for this article.

Electronically published June 1, 2007
In contrast to previous research, the goal of this article is to examine how context affects intuitive choice processes. In particular, we examine a scenario in which adding inferior options can influence choice by changing the perceptual characteristics of the set, making one option perceptually focal. We refer to this as the "perceptual focus effect." In this context, we find that adding fully dominated options to a set can significantly decrease-rather than increase-preference for an asymmetrically dominating option in favor of a perceptually focal option.

Building on the notion that individuals employ two modes of processing when making decisions (Hogarth 2001; Kahneman and Frederick 2002; Sloman 1996), we expect that the observed effect of adding dominated options on choice will be a function of the mode of processing. In this context, we argue that the perceptual focus effect is less pronounced when choices are made using more analytic processing than when using relatively more intuitive processing.

We investigate the perceptual focus effect in a series of four empirical studies. The first experiment examines the perceptual focus effect by documenting that adding inferior options to a choice set can reverse the attraction effect and that this outcome is moderated by mode of processing. Building on this finding, the second experiment provides direct support for the perceptual nature of the effect by demonstrating that perceptual focus is sensitive to subtle visual changes in the choice context. The third experiment provides an alternative test of the research hypotheses by examining the impact of perceptual focus on attribute preferences. Finally, the fourth experiment uses a resource-depletion paradigm to explicitly document that the impact of adding inferior options on choice is moderated by the mode of processing. The article concludes with a discussion of the theoretical implications of this research. 


\section{THEORETICAL BACKGROUND}

This research examines a scenario in which a core set of options is expanded by adding alternatives that change the perceptual characteristics of the set, making one of the core options perceptually focal. We test the impact of the perceptual characteristics of a set on choice in the context of the attraction effect (Huber et al. 1982; Huber and Puto 1983; Simonson 1989). The attraction effect can be illustrated by starting with a binary set of two-dimensional alternatives, $\mathrm{A}$ and $\mathrm{B}$, such that $\mathrm{A}$ is superior on one of the attributes and $\mathrm{B}$ is superior on the other, as shown in figure 1. For example, if both attributes were rated on the same 100 -point scale, A might be rated $(60,80)$ and $\mathrm{B}(80,60)$. Previous work on the attraction effect has demonstrated that adding an option to this binary set, which is asymmetrically dominated by only one of the options, will tend to increase the choice share of the option that dominates it. Thus, option $\mathrm{C}$, with attribute values $(75,60)$, would be dominated by $\mathrm{B}$ but not by $\mathrm{A}$. It has been shown that option $\mathrm{B}$ tends to be more attractive in the three-option set ABC than in the twooption set $\mathrm{AB}$.

Now consider a scenario in which the binary set is expanded by adding three new options, option $\mathrm{C}$ as above, plus $\mathrm{D}(55,60)$ and $\mathrm{E}(50,60)$, which are dominated by both options in the core set. Existing theory predicts no change in the relative preference for the asymmetrically dominated option $\mathrm{B}$, based on adding two fully dominated options. Table 1 includes options A, B, C, D, and E with the attribute values mentioned above. Note that, in this example, options B, C, D, and E share a common value on one attribute. The assumption in this research is that a re-

\section{FIGURE 1}

\section{THE ATTRACTION AND PERCEPTUAL FOCUS EFFECTS}

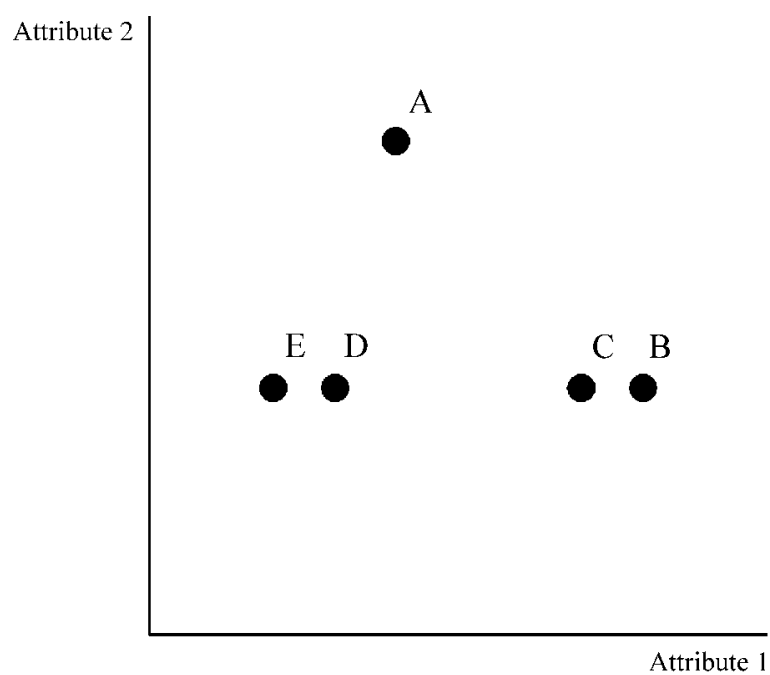

NotE.-Options A and B make up the core set. Option C is asymmetrically dominated by $B$, and options $D$ and $E$ are dominated by both the alternatives in the core set. Option $A$ is the only alternative with a unique value on attribute 2 .
TABLE 1

ILLUSTRATION OF THE EXPERIMENTAL STIMULI

\begin{tabular}{lccccc}
\hline \hline & $\begin{array}{c}\text { Option } \\
\text { A }\end{array}$ & $\begin{array}{c}\text { Option } \\
\text { B }\end{array}$ & $\begin{array}{c}\text { Option } \\
\text { C }\end{array}$ & $\begin{array}{c}\text { Option } \\
\text { D }\end{array}$ & $\begin{array}{c}\text { Option } \\
\text { E }\end{array}$ \\
\hline Attribute 1 & 60 & 80 & 75 & 55 & 50 \\
Attribute 2 & 80 & 60 & 60 & 60 & 60 \\
\hline
\end{tabular}

NOTE.-The repetition of common values on attribute 2 is designed to draw attention to option A, making it perceptually focal and thereby increasing its choice share.

peated common attribute value can draw attention to the only alternative with a unique value. In this way, the perceptual characteristics of the choice set can make one option perceptually focal.

This proposition is consistent with the Gestalt principle of grouping by similarity (Baylis and Driver 1992; Quinlan and Wilton 1998; Wertheimer 1923/1999), which builds on the notion of similarity assessment as a core informationprocessing heuristic. Of particular relevance to the proposed perceptual focus effect is the notion that people tend to group together perceptually similar elements of a display. This grouping together of similar elements may cause dissimilar elements to pop out (Duncan and Humphreys 1989; Kahneman 1973; Treisman and Gelade 1980), attracting the decision maker's attention to one option or attribute value.

Drawing on these findings, we propose that making one option perceptually focal can increase the preference for that option. This prediction is consistent with the finding that focusing attention on a particular option in a set can increase its attractiveness and the likelihood of its being chosen (Chernev 2005a; Dhar and Simonson 1992; see also Tversky 1977). For example, Dhar and Simonson (1992) found that when respondents were specifically asked to evaluate one option in a binary set prior to choice, they tended to give higher ratings to the focal option and to choose it more often than the nonfocal option. We propose that similar effects may be found simply by drawing attention to an option through the perceptual similarity of alternatives in the set.

The proposition that the perceptual characteristics of the choice set can make one option focal and thereby affect choice is derived from the assumption that consumers process information in a way that makes perceptual characteristics salient. Recent decision research has argued that people may employ two modes of information processing: intuitive and analytic (Epstein et al. 1992; Hogarth 2001; Kahneman and Frederick 2002; Sloman 1996). The intuitive mode (also referred to as System 1; Kahneman 2003) is automatic, effortless, rapid, and associative; it controls such basic processes as attention and perception. In contrast, the analytic mode (referred to as System 2) is deliberate, relatively effortful, and contingent on the availability of cognitive resources; it controls such higher order processes as logic and reasoning.

Building on the dual-mode-of-processing paradigm, we expect that the perceptual focus effect is likely to be a function of consumers' mode of processing. Indeed, if adding 
dominated options to a choice set can make one option perceptually focal, then this impact should be a function of the nature of consumers' decision processes. As a result, we argue that the perceptual focus effect should be less pronounced when consumers engage in a relatively more analytic mode of processing.

To summarize, in this research we propose that adding options to a set can influence choice by changing the perceptual characteristics of the set. In particular, we posit that adding options that make one alternative perceptually focal can increase its attractiveness and its relative choice share, even when the choice set includes an asymmetrically dominating option. We further expect that this perceptual focus effect is a function of the nature of consumers' information processes, such that it is likely to be less pronounced for individuals evaluating the available information in a more analytic fashion. We test these predictions in a series of four experiments described in more detail in the following sections.

\section{EXPERIMENT 1}

Experiment 1 was designed to test empirically the proposition that changing the perceptual choice context by adding options can influence preferences. In particular, we examine whether the perceptual characteristics of the choice set can reverse the attraction effect. We first replicate the attraction effect by adding an asymmetrically dominated option to a binary set. We then demonstrate that adding fully dominated options to this set can weaken the attraction effect by making a different option perceptually focal. We further examine whether the proposed effect of adding dominated options is moderated by the mode of processing.

\section{Method}

One hundred and fourteen students from Northwestern University were recruited to participate in an online experiment. Participants were randomly assigned to one of four experimental conditions. Participants in the first condition were presented with a binary set of options described on two attributes (set AB), such that the first option was superior on one of the dimensions and the second option was superior on the other (e.g., options A and B in table 1). Participants in the second condition chose from a set in which a third, asymmetrically dominated option had been added to the set (set ABC).

Participants in the third condition chose from a five-option set (set ABCDE) in which two additional options were added to the set. Both D and E were fully dominated: they were inferior to all other options in the set. Further, the choice sets were designed so that options C, D, and E all shared a common attribute value with option $\mathrm{B}$. Thus, option $\mathrm{A}$ was the only option with a dissimilar attribute value on one attribute. It is proposed that such a pattern of similar attribute values will tend to draw attention to option $\mathrm{A}$.

To examine the impact of mode of processing on the proposed perceptual focus effect, respondents in the fourth condition were given the same five-option choice set (set ABCDE) but were asked to justify their decisions, a procedure similar to that used in prior research (Simonson 1989; Simonson and Nowlis 2000). It was anticipated that asking participants to justify their choices would make it more likely that they would rely more on an analytic mode of processing when making their choices. Previous research suggests that the reason-based processing encouraged by choice justification is a hallmark of the analytic mode of processing (Sloman 1996). In this context, we expected that, if the proposed effect was indeed driven by the perceptual properties of the decision set, then it should be less pronounced for individuals asked to justify their decision. Specifically, since previous research has shown that reasonbased choice tends to strengthen the preference for an asymmetrically dominating option (Simonson 1989), we expected that option A would lose choice share to option B when participants were asked to justify their choices.

Once assigned to an experimental condition, participants were asked to select one option from each of four choice sets (sunglasses, MP3 players, sofas, and cell phones-see app. A for a summary of the stimuli). All attributes were rated on a 100-point scale, with 100 as the best. Participants in the choice justification condition were given space below each choice to list the reasons for their selection. At the end of the experiment, participants were debriefed, thanked, and paid $\$ 5$ for participating.

\section{Results}

Each of the 114 participants made four choices, yielding a total of 451 observations (five missing data points). Given that the dependent measure of interest was the relative choice shares of options A and B, we eliminated 20 observations (4\% of the total) in which participants indicated a preference for one of the inferior options $\mathrm{C}, \mathrm{D}$, or $\mathrm{E}$, a procedure consistent with prior research (Huber et al. 1982; Simonson 1989). Thus, the final data set used to test the experimental predictions consisted of 431 observations.

The choice shares of option A relative to option B, summarized in table 2, are consistent with our experimental predictions. To illustrate, in the sofa category, $42.3 \%$ of participants who chose from the core set $\mathrm{AB}$ preferred option A. When an asymmetrically dominated option $C$ was added to form set $\mathrm{ABC}$, the attraction effect predicts that $\mathrm{B}$ should be perceived as more attractive, resulting in a decrease in the relative share of $\mathrm{A}$. Consistent with previous research, the relative share of option A dropped to $26.1 \%$. When three additional options (one asymmetrically dominated and two fully dominated) were added to the binary set, however, the choice share of A increased to $77.4 \%$. This shift in preferences is consistent with the hypothesis that adding the dominated options caused A to become perceptually focal. Finally, when respondents were asked to provide the rationale for their choice, encouraging them to use more analytic processing, the choice share of option A dropped to $36.0 \%$.

The significance of these results was tested using logistic regression models predicting choice as a function of decision 
TABLE 2

RELATIVE CHOICE SHARES OF THE PERCEPTUALLY FOCAL OPTION AS A FUNCTION OF SET SIZE AND MODE OF PROCESSING (EXPERIMENT 1)

\begin{tabular}{|c|c|c|c|c|}
\hline & \multicolumn{4}{|c|}{ Experimental condition } \\
\hline & $\begin{array}{c}\text { Two-option set (AB) } \\
(\%)\end{array}$ & $\begin{array}{c}\text { Three-option set (ABC) } \\
(\%)\end{array}$ & $\begin{array}{c}\text { Five-option set } \\
\text { (ABCDE) } \\
(\%)\end{array}$ & $\begin{array}{l}\text { Five-option set } \\
\text { (ABCDE) with } \\
\text { justification } \\
(\%)\end{array}$ \\
\hline Sunglasses & $\begin{array}{c}57.7 \\
(N=26)\end{array}$ & $\begin{array}{c}23.1 \\
(N=26)\end{array}$ & $\begin{array}{c}77.4 \\
(N=31)\end{array}$ & $\begin{array}{c}30.8 \\
(N=26)\end{array}$ \\
\hline MP3 player & $\begin{array}{c}25.9 \\
(N=27)\end{array}$ & $\begin{array}{c}19.2 \\
(N=26)\end{array}$ & $\begin{array}{c}61.3 \\
(N=31)\end{array}$ & $\begin{array}{c}8.3 \\
(N=24)\end{array}$ \\
\hline Sofa & $\begin{array}{c}42.3 \\
(N=26)\end{array}$ & $\begin{array}{c}26.1 \\
(N=23)\end{array}$ & $\begin{array}{c}77.4 \\
(N=31)\end{array}$ & $\begin{array}{c}36.0 \\
(N=25)\end{array}$ \\
\hline Cell phone & $\begin{array}{c}46.1 \\
(N=26)\end{array}$ & $\begin{array}{c}37.5 \\
(N=24)\end{array}$ & $\begin{array}{c}48.5 \\
(N=33)\end{array}$ & $\begin{array}{c}42.3 \\
(N=26)\end{array}$ \\
\hline Combined & 42.9 & 26.3 & 65.9 & 29.7 \\
\hline
\end{tabular}

NOTE.-Results reported are the choice shares of the perceptually focal option A relative to the asymmetrically dominating option $B$. In the $A B, A B C$, and $A B C D E$ conditions, participants were simply asked to choose one option from the set. In the ABCDE with justification condition, participants were also asked to provide reasons for their choices.

set, product category, and their interaction. The first test confirmed a replication of previous work on the attraction effect, such that, across categories, option A was significantly less preferred in the set $\mathrm{ABC}(26.3 \%)$ than in the core set $\mathrm{AB}\left(42.9 \% ; \chi^{2}(1)=5.83, p<.05\right)$. The effect of category and the category-by-decision set interaction were not significant.

Next, we examined whether adding fully dominated options to this set could reduce the strength of the attraction effect by making A perceptually focal. The data show that, across categories, the relative choice share of option A increased, from $26.3 \%$ in set $\mathrm{ABC}$ to $65.9 \%$ in set $\mathrm{ABCDE}$. Analysis shows that this difference was significant $\left(\chi^{2}(1)=33.31, p<.001\right)$. In fact, more than just reducing the strength of the attraction effect, the results suggest a de facto preference reversal, such that the choice share of $\mathrm{A}$ was significantly greater in the set ABCDE (65.9\%) than in the core set $\mathrm{AB}\left(42.9 \% ; \chi^{2}(1)=12.83, p<.001\right)$. These findings are consistent with the hypothesis that adding dominated options can systematically increase the attractiveness of a perceptually focal option.

To test the prediction that the perceptual focus effect is a function of mode of processing, we examined whether the observed effects were moderated by instructions to justify choice. The data show that, when choosing from the fiveoption set ABCDE, the choice share of option A was significantly lower among respondents who were asked to justify their decisions $(29.7 \%)$ than among participants simply asked to choose from the same set $\left(65.9 \% ; \chi^{2}(1)=\right.$ $28.75, p<.001)$. This finding lends support to the prediction that the observed perceptual focus effect is contingent on individuals' mode of processing, such that the observed effect is less pronounced when people must justify their choices. In fact, when participants were asked to justify their choices from the five-option set, the choice share of option A was significantly lower $(29.7 \%)$ than in the core set AB $\left(42.9 \% ; \chi^{2}(1)=4.86, p<.05\right)$, a result consistent with a re-emergence of the attraction effect when participants were engaged in reason-based, analytic processing.

\section{Discussion}

The data from experiment 1 lend support to the proposition that adding options that change the perceptual characteristics of the choice set can make one option perceptually focal. Consistent with the theoretical predictions, we found that in the context of the attraction effect, the nondominating option can be made perceptually focal by adding inferior options to the decision set, thus increasing the likelihood of its being chosen and decreasing the strength of the attraction effect. Moreover, we document that the observed perceptual focus effect was a function of individuals' mode of processing, such that these effects were less pronounced for respondents using an analytic mode of processing.

Research on the role of information displays in choice suggests a potential alternative explanation for the results of experiment 1 . This research has shown that an increase in the number of attribute levels on a given dimension leads to an increase in the information load, as evidenced by an increase in processing time and a reduction in decision quality (Lurie 2004). This suggests that an attribute with more levels may be more difficult to process relative to an attribute with fewer levels. Thus, consumers who are seeking to minimize effort could adopt a choice strategy based on simply selecting the option that dominates on the attribute that is easiest to evaluate.

In experiment 1 , we identified the perceptual focus effect by making one value on an attribute unique and the rest common. A consequence of this manipulation was to reduce the variance on that dimension. Thus, in the example in table 1 , the choice set is rated on five different levels on the first attribute but only on two levels on the second at- 
tribute. As a result, one could argue that participants may prefer option A not because it is perceptually focal but because it dominates on the second attribute, which is easier to evaluate and is therefore weighted heavier in choice.

To rule out this alternative explanation, we designed experiment 2 to explicitly vary the perceptual characteristics of identical choice sets in a way that would emphasize or attenuate the visual pattern that focuses attention on one option. In particular, we sought to moderate the strength of the perceptual focus effect by using visual cues to encourage participants to assess values in an attribute-by-attribute fashion or in an alternative-by-alternative fashion (Chernev 2005a). We expected that by-attribute processing would perceptually emphasize the unique attribute value in contrast to the repeated common values, thus strengthening the perceptual focus effect. In contrast, by-alternative processing should make the perceptually unique attribute value less salient, thereby weakening the perceptual focus effect. Because this manipulation of perceptual organization does not change the number of levels on each attribute, a theory based on overweighting of low-variance attributes would predict no difference in preferences based on adding visual cues to the choice set.

\section{EXPERIMENT 2}

Experiment 2 was designed to provide support for the perceptual focus effect by explicitly manipulating the perceptual characteristics of the choice set. We expected that perceptual cues encouraging by-alternative processing would weaken the perceptual focus effect. In contrast, byattribute processing should make the focal option's unique value more salient, thereby increasing the strength of the perceptual focus effect relative to by-alternative processing. Additionally, this experiment sought to extend the generalizability of the results by testing the perceptual focus effect using both numeric and nonnumeric rating scales. The experimental method, data, and analyses are presented in more detail in the following sections.

\section{Method}

Participants were 150 students from Northwestern University who completed an online survey on consumer decision making. They were given a choice task involving either three-option or five-option decision sets that consisted of light bulbs, microwaves, MP3 players, and shirts. As in experiment 1 , all choice sets included one perceptually focal option, referred to as A, and one asymmetrically dominating option, referred to as B. In order to investigate whether the perceptual focus effect was limited to just numerical attribute values, we also included nonnumeric attribute values among the stimuli. In particular, microwaves were rated on a 100-point scale (as in experiment 1), but shirts were rated on a scale of one to five stars, MP3 players were rated on a scale based on pie charts, and light bulbs were rated on a smiley-frowny face scale (see app. B for details).

Participants were randomly assigned to the conditions of a 2 (set size: three options vs. five options) $\times 2$ (perceptual organization: by attribute vs. by alternative) factorial design. In each condition, participants made four choices, one from each product category. All participants in the three-option set condition chose from the same three options. In a similar manner, all participants in the five-option set condition chose from the sets consisting of the alternatives in the three-option set condition plus two additional fully dominated options.

In the by-attribute condition, the choice sets included horizontal lines separating attributes values in each row. These lines perceptually divided the table into rows, encouraging by-attribute processing. In the by-alternative condition, on the other hand, the choice sets included vertical lines separating each of the options. These lines perceptually divided the table into columns, encouraging by-alternative processing. After making their choices, respondents were debriefed and paid a nominal sum for participating.

\section{Results}

Each of the 150 participants made four choices, yielding 593 observations (seven missing data points). Given that the dependent measure of interest was the change in the relative shares of options $\mathrm{A}$ and $\mathrm{B}$, we eliminated $35 \mathrm{ob}-$ servations (6\% of the total) in which participants indicated a preference for options C, D, or E. Thus, the final data set used to test the experimental predictions consisted of 558 observations.

The choice share data, summarized in table 3, are consistent with our experimental predictions. When the choice sets in the light bulb category were organized by attribute (i.e., with horizontal lines separating the attribute values), the relative choice share of the perceptually focal option A was $40.0 \%$ among participants choosing from the threeoption set $\mathrm{ABC}$. Consistent with the findings from experiment 1 , when two dominated options were added to form the set ABCDE, the relative choice share of option A increased to $81.0 \%$. As expected, this effect was reduced by organizing the same choice set in a by-alternative fashion (i.e., with vertical lines separating the attribute values). When choosing from the three-option set organized by alternative, the relative choice share of option A was $46.2 \%$, compared with $40.0 \%$ among participants choosing from the five-option set.

The significance of these results was tested using logistic regression models predicting choice of $\mathrm{A}$ or $\mathrm{B}$ as a function of perceptual organization (by attribute vs. by alternative), set size (three options vs. five options), product category, and their interactions. Lending support to the main experimental prediction, there was a significant interaction between perceptual organization and set size $\left(\chi^{2}(1)=\right.$ $15.98, p<.001)$. Thus, although there was a significant increase in preference for option $\mathrm{A}$ when the sets were organized by attribute $(\mathrm{ABC}=29.6 \%$ vs. $\mathrm{ABCDE}=$ $\left.62.7 \% ; \chi^{2}(1)=31.65, p<.001\right)$, there was no difference when they were organized by alternative $(\mathrm{ABC}=35.4 \%$ vs. $\left.\mathrm{ABCDE}=32.5 \% ; \chi^{2}(1)<1\right)$. Lending further support to the prediction that perceptual organization moderates the 
TABLE 3

RELATIVE CHOICE SHARES OF THE PERCEPTUALLY FOCAL OPTION AS A FUNCTION OF SET SIZE AND PERCEPTUAL ORGANIZATION (EXPERIMENT 2)

\begin{tabular}{|c|c|c|c|c|}
\hline \multirow[b]{2}{*}{$\begin{array}{l}\text { Perceptual } \\
\text { organization }\end{array}$} & \multicolumn{2}{|c|}{ By attribute } & \multicolumn{2}{|c|}{ By alternative } \\
\hline & $\begin{array}{c}\text { Three-option } \\
\text { set (ABC) } \\
(\%)\end{array}$ & $\begin{array}{c}\text { Five-option } \\
\text { set (ABCDE) } \\
(\%)\end{array}$ & $\begin{array}{c}\text { Three-option } \\
\text { set (ABC) } \\
(\%)\end{array}$ & $\begin{array}{c}\text { Five-option } \\
\text { set }(A B C D E) \\
(\%)\end{array}$ \\
\hline Light bulb & $\begin{array}{c}40.0 \\
(N=35)\end{array}$ & $\begin{array}{c}81.0 \\
(N=42)\end{array}$ & $\begin{array}{c}46.2 \\
(N=39)\end{array}$ & $\begin{array}{c}40.0 \\
(N=30)\end{array}$ \\
\hline Microwave & $\begin{array}{c}32.4 \\
(N=34)\end{array}$ & $\begin{array}{c}59.0 \\
(N=39)\end{array}$ & $\begin{array}{c}38.2 \\
(N=34)\end{array}$ & $\begin{array}{c}31.0 \\
(N=29)\end{array}$ \\
\hline MP3 player & $\begin{array}{c}13.9 \\
(N=36)\end{array}$ & $\begin{array}{c}46.0 \\
(N=37)\end{array}$ & $\begin{array}{c}10.8 \\
(N=37)\end{array}$ & $\begin{array}{c}15.4 \\
(N=26)\end{array}$ \\
\hline Shirt & $\begin{array}{c}32.4 \\
(N=37)\end{array}$ & $\begin{array}{c}62.5 \\
(N=40)\end{array}$ & $\begin{array}{c}47.1 \\
(N=34)\end{array}$ & $\begin{array}{c}41.4 \\
(N=29)\end{array}$ \\
\hline Combined & 29.6 & 62.7 & 35.4 & 32.5 \\
\hline
\end{tabular}

NOTE.-Results reported are the choice shares of the perceptually focal option A relative to the asymmetrically dominating option B.

strength of the perceptual focus effect, preference for option $\mathrm{A}$ in the set ABCDE was significantly higher when the sets were organized by attribute $(62.7 \%)$ than when the sets were organized by alternative $\left(32.5 \% ; \chi^{2}(1)=24.17, p<.001\right)$.

The analysis also revealed a significant main effect of set size $\left(\chi^{2}(1)=12.19, p<.001\right)$, indicating that the perceptually focal option A was more preferred in the five-option set than in the three-option set. This result is consistent with the findings of experiment 1 . As predicted, there was also a significant effect of perceptual organization on choice $\left(\chi^{2}(1)=8.55, p<.005\right)$, such that option A was more preferred when sets were organized by attribute than by alternative.

These results were consistent across product categories. Although there was a significant main effect of product category $\left(\chi^{2}(3)=29.15, p<.001\right)$, the product category variable did not interact with either of the other factors and the three-way interaction was not significant $(p>.40)$. Overall, these findings lend support to the prediction that the observed perceptual focus effect is indeed contingent on the perceptual properties of the choice set.

\section{Discussion}

The results of experiment 2 provide additional support for the perceptual focus effect and show that it is robust across both numeric and nonnumeric scales. These results also rule out an alternative explanation suggested by the information display literature. Although previous research suggests that under certain conditions consumers may overweight attributes with low variance, this cannot account for the results of experiment 2. Specifically, we held the variance on each attribute constant across experimental conditions while varying the perceptual characteristics in a way that would emphasize or attenuate the visual pattern that focuses attention on one option. Whereas an account involving overweighting of low-variance attributes would predict no change in preferences based on the addition of horizontal or vertical lines to the display, we find that the perceptual focus effect is influenced by perceptual changes to the choice sets.

Overall, the first two experiments show that the perceptual focus effect is a function of both mode of processing and the perceptual characteristics of the choice set. Both experiments tested the effect by adding dominated options and examining their impact on options' choice shares. An alternative approach to testing this effect is to investigate its influence on consumer preferences for product attributes. This approach is based on the assumption that, when choice involves making a trade-off, selection of an option reveals the relative preference for an attribute. In this research, we propose that the perceptual focus effect may influence consumer's revealed attribute preferences. Specifically, we expect that a tendency to prefer perceptually focal options could lead to choices that reveal inconsistent attribute preferences.

To illustrate, consider a scenario in which consumers are faced with three choice sets from the same product category. The options in each set are described by attributes $X$ and $\mathrm{Y}$, attributes $\mathrm{Y}$ and $\mathrm{Z}$, or attributes $\mathrm{Z}$ and $\mathrm{X}$, respectively. Suppose that each choice includes two nondominated options and that choosing between them requires making a trade-off. Further, suppose that one of these alternatives is a perceptually focal option that is superior on attribute $\mathrm{X}$ in the first set, attribute $\mathrm{Y}$ in the second, and attribute $\mathrm{Z}$ in the third. A consumer who chooses the perceptually focal option in all three of these sets would make inconsistent attribute-based choices. Specifically, selecting the perceptually focal option in all three sets would lead to choices indicating that attribute $\mathrm{X}$ is preferred to attribute $\mathrm{Y}$, attribute $\mathrm{Y}$ is preferred to attribute $\mathrm{Z}$, and attribute $\mathrm{Z}$ is preferred to attribute $\mathrm{X}$.

We expect this effect to be moderated by mode of processing, such that the inconsistent attribute preferences will be less pronounced for consumers using an analytic mode of processing than for consumers using an intuitive mode of processing. Specifically, if the proposed inconsistent pref- 
erences may indeed be attributed to a preference for perceptually focal options, then we would expect fewer inconsistent preferences among individuals who use a relatively more analytic mode of processing when making decisions.

\section{EXPERIMENT 3}

Experiment 3 was designed to test the proposition that consumers' attribute preferences can be influenced by the perceptual characteristics of the choice set. Specifically, we expected the perceptual focus effect to lead to inconsistent attribute preferences. Further, we expected that preference inconsistency would be a function of the mode of processing.

\section{Method}

Eighty-four students from Northwestern University were recruited to participate in an online survey on consumer decision making. Participants were asked to imagine that they were purchasing two products, vitamin water and a digital camera, and had to make three choices in each product category. Choice sets consisted of five alternatives, each described on two attributes, with each set containing one perceptually focal option A and one asymmetrically dominating option B. Attribute values within each of the product categories were the same for all three choices, although the attributes varied. In each category three attributes were rotated, such that each of the three choice sets contained a different combination of attributes (see app. C for more detail). To illustrate, when choosing vitamin water, respondents were given a choice set described by the attributes "endurance" and "energy," a second choice set described by "energy" and "stress relief," and, finally, a set in which options were described by "stress relief" and "endurance." To control for potential learning effects, the order of presentation within each product category was counterbalanced across respondents.

Respondents were randomly assigned to one of two modeof-processing conditions. In the no-justification condition, participants were simply instructed to make a choice from each set. Based on the findings from experiment 1 , we anticipated that participants in this condition would rely relatively more on an intuitive mode of processing when making their choices and would be more likely to prefer perceptually focal options. To encourage participants to rely on intuitive processing, we placed a picture of a small clock in the corner of every page, a manipulation similar to those used in prior research to successfully increase anticipated time pressure (Dhar and Nowlis 1999). It was expected that since the analytic mode of processing is slower and more resource demanding than the intuitive mode (Hogarth 2001), participants would be more likely to engage in intuitive rather than analytic processing if they felt they were under time pressure.

In the choice-justification condition, in contrast, participants were asked to provide a rationale for their choices, as in experiment 1 . Again, it was anticipated that participants who had to justify their choices would be more likely to engage in reason-based processing and therefore would be more likely to use an analytic mode. Participants were asked to choose one option from each choice set; thus, each individual made six choices in total. At the end of the survey, respondents were debriefed and paid $\$ 5$ for participating.

\section{Results}

To examine whether the perceptual focus effect can influence the consistency of attribute preferences, we looked at the number of intransitive choices in each mode-of-processing condition. Transitivity is a property of preferences, such that for any three product attributes $X, Y$, and $Z$, the preference relation is transitive in cases when $X>Y, Y>$ $Z$, then $X>Z$. Intransitive preferences would be revealed in instances when $X>Y, Y>Z$, then $Z>X$ (Kivetz and Simonson 2000; Tversky 1969). Each time a participant selected the perceptually focal option A in all three choices, it was counted as one intransitive choice. To illustrate, when choosing among sets of digital cameras, one choice indicating that "features" was more important than "resolution," another indicating that "resolution" was more important than "memory," and a third indicating that "memory" was more important than "features" would be counted as one intransitive choice.

When choosing among sets of digital cameras, $26.2 \%$ $(N=42)$ of participants in the no-justification condition made intransitive choices by selecting option $\mathrm{A}$ in all three choices. In contrast, among participants asked to justify their choices, none $(N=42)$ chose option A in all three choices. Analysis revealed that this difference was significant $(z=$ $3.56, p<.001)$. Similar results were revealed in the vitamin water category. Specifically, $31.0 \%(N=42)$ of participants in the no-justification condition made intransitive choices, compared with zero $(N=42)$ in the choice-justification condition $(z=3.92, p<.001)$.

Another way of testing the significance of these results is to evaluate the number of people who chose option A from all three choice sets (A-intransitive) against a suitable benchmark, such as the number of participants in each condition who chose option B in all three choices (B-intransitive). The perceptual focus effect would only predict intransitivity based on repeated choice of perceptually focal options (i.e., A-intransitivity). If intransitive choices are the result of some process other than the perceptual focus effect (e.g., guessing), then we would expect no difference between rates of Aintransitivity and B-intransitivity. This procedure is similar to previous methods of testing the significance of intransitivity (Chernev 2005b; Kivetz and Simonson 2000).

When making choices in the digital camera category, $26.2 \%$ of participants in the no-justification condition made A-intransitive choices, compared with no participants who made B-intransitive choices, a difference that was significant $(z=3.56, p<.001)$. The same pattern of results was revealed in the vitamin water category $(31.0 \%$ vs. $2.4 \%, z=$ $3.51, p<.001)$. As predicted, the difference between A-intransitive and B-intransitive choices was not significant in the 
choice-justification condition. Specifically, when participants were asked to justify their choices there was no difference in rates of A-intransitivity and B-intransitivity in either the digital camera category, where there were no intransitive choices, or in the vitamin water category (A-intransitivity $=2.4 \%$ vs. B-intransitivity $=0 \%, z=1.01)$. These data are consistent with our experimental predictions.

In addition to looking at the consistency of choices made by each subject, we also examined the influence of mode of processing on each individual choice. When evaluated at the level of individual choices, the data in experiment 3 are similar to the two five-option conditions in experiment 1: choice from the set ABCDE with and without instructions to justify. Each of the 84 participants made three choices in two product categories, yielding a total of 504 observations. Because we were interested in the change in the relative shares of options A and B, 49 observations (10\% of the total) in which respondents chose options $\mathrm{C}, \mathrm{D}$, or $\mathrm{E}$ were eliminated from analysis. Thus, the final data set used to test the experimental predictions consisted of 455 observations.

The data reveal that participants in the intuitive processing condition were more likely than participants in the analytic processing condition to prefer the perceptually focal option in any individual choice. When choosing among sets of vitamin water, $64.0 \%$ of respondents in the no-justification condition preferred the perceptually focal option across all three choice sets, compared to $53.1 \%$ of participants asked to justify their choices. Likewise, when choosing a digital camera, $65.8 \%$ of respondents in the no-justification condition preferred the perceptually focal option, while only $46.5 \%$ of participants selected the perceptually focal option when justifying choice. Analysis reveals that the effect of mode of processing was significant $\left(\chi^{2}(1)=10.52, p<\right.$ $.005)$, suggesting that the perceptually focal option was appreciably less attractive to participants justifying their choices. These results are consistent with the findings from experiment 1 .

\section{Discussion}

Experiment 3 examined the proposition that consumers' attribute preferences can be influenced by the perceptual characteristics of the choice set. Specifically, the results showed that the perceptual focus effect could lead to intransitive attribute preferences. Further, we found that this preference intransitivity was moderated by the mode of processing, such that there were no intransitive choices among participants using relatively analytic processing.

Note that an alternative explanation based on participants shifting to an attribute-based decision strategy cannot adequately explain the data. Although, previous research has shown that, under time pressure, consumers often adopt a lexicographic decision rule (Payne, Bettman, and Luce 1996), since the stimuli were not designed so that any one attribute would dominate, it is unlikely that the majority of participants would systematically choose the same attribute when shifting to a lexicographic strategy. Furthermore, there were three attributes used for each category, and these attributes were rotated through the choice sets in pairs. A lexicographic strategy would predict consistent choices based on the relative importance of the attributes rather than the intransitive attribute preferences revealed in experiment 3 .

The experiments so far provide converging evidence for the moderating role of mode of processing on choice. Thus, we have shown that, when participants were simply asked to choose, they were more likely to prefer a perceptually focal option, even in the presence of an asymmetrically dominated option. In contrast, those who were required to rely more on an analytical mode, such as when justifying their choices, displayed a stronger preference for an asymmetrically dominating option over a perceptually focal one.

An alternative strategy for investigating the moderating role of mode of processing on the perceptual focus effect is to prime respondents with a prechoice task designed to activate either more intuitive or more analytical processing. Engaging in an analytic task (e.g., solving addition problems) prior to choice might cause a carryover effect, such that individuals would use relatively more analytic processing when making a subsequent choice. Thus, performing a task requiring analytic processing (e.g., arithmetic) might weaken the preference for a perceptually focal option in a subsequent choice task. In contrast, performing a perceptually oriented task (e.g., looking at pictures) might encourage the use of more intuitive and less analytic processing. As a result, performing a perceptual task prior to choice might strengthen the preference for a perceptually focal option in a subsequent decision task.

Recent research on depletion, however, suggests that analytic tasks may not always increase the use of the analytic mode of processing in subsequent tasks. Specifically, performing an excessive amount of analytic processing (e.g., doing too much arithmetic) might deplete an individual of cognitive resources (Baumeister et al. 1998; Vohs et al. 2006). Since deliberate, analytic processing is resource demanding and automatic intuitive processing is not, we use a depletion task as an alternate manipulation to encourage individuals to rely more on intuitive processing. Thus, performing too much of an analytic task prior to choice is expected to strengthen the preference for a perceptually focal option in a subsequent decision task. We test these predictions in experiment 4.

\section{EXPERIMENT 4}

The purpose of experiment 4 is to provide further support for the proposition that the impact of the perceptual similarity of options on choice is moderated by mode of processing. This experiment used priming tasks to examine how performing an analytic task, an intuitive task, or a resourcedepleting analytic task before choice affects later preference for perceptually focal options. The experimental method, data, and analyses are presented in more detail in the following sections. 


\section{Method}

Participants consisted of 114 students from Northwestern University who completed an online survey on consumer decision making. They were given a choice task that involved five-option decision sets consisting of digital cameras and massage chairs. In all conditions, participants were presented with the same two choice sets. Both of the choice sets included one perceptually focal option, A, and one asymmetrically dominating option, B.

Participants were randomly assigned to one of three experimental conditions. In all conditions, mode of processing was manipulated by priming respondents with an initial task designed to activate either intuitive or analytical processing. Respondents in the analytic condition were given an initial task with five arithmetic problems that consisted of adding together two three-digit numbers, a task conceptually similar to those used in prior research (Garbarino and Edell 1997).

In contrast, respondents in the intuitive condition were primed with predecision tasks aimed at inducing intuitive rather than analytical processing. One of the intuitive conditions was a perceptual problem task that involved looking at a series of five pictures. Each picture was an optical illusion that could appear as one of two different images, depending on one's perspective. For example, one of the images was the Necker Cube (Bradley and Petry 1977), a three-dimensional wire representation of a cube with a colored dot on one of the corners. From one perspective, the dot appeared on the front corner of the cube; from a different perspective, the dot was on the back corner. For each picture, participants were simply asked to indicate which of the two images they saw first.

In the third condition, respondents were given a resourcedepleting task that was expected to lead to more intuitive processing. The task was identical to the analytic task except that the total number of problems given to respondents was 15 instead of five. This manipulation was designed to deplete participants' resources, making it less likely that they would subsequently engage in the resource-demanding analytical mode of processing. Following completion of one of the three manipulation tasks, participants were asked to select one option from each product category, resulting in two choices by each participant. After making their choices, participants were debriefed and paid $\$ 5$.

\section{Results}

One hundred and fourteen participants made one choice from each of two product categories, yielding a total of 226 observations (two missing data points). Because the dependent measure of interest was the relative choice share of $\mathrm{A}$ and B, 21 observations (9\% of the total) were excluded from the analysis because the participants chose options $\mathrm{C}$, $\mathrm{D}$, or E. Thus, the final data set used to test the experimental predictions consisted of 205 observations.

The choice share data, broken out by product category, are summarized in table 4. To examine the impact of mode of processing on the strength of the perceptual focus effect,
TABLE 4

CHOICE SHARE OF THE PERCEPTUALLY FOCAL OPTION AS A FUNCTION OF MANIPULATION TASK (EXPERIMENT 4)

\begin{tabular}{|c|c|c|c|}
\hline & \multicolumn{3}{|c|}{ Mode-of-processing manipulation } \\
\hline & $\begin{array}{c}\text { Intuitive } \\
\text { (perceptual task) } \\
(\%)\end{array}$ & $\begin{array}{c}\text { Analytic } \\
\text { (five-problem } \\
\text { task) } \\
(\%)\end{array}$ & $\begin{array}{c}\text { Depletion } \\
\text { (15-problem } \\
\text { task) } \\
(\%)\end{array}$ \\
\hline Digital camera & $\begin{array}{c}37.1 \\
(N=35)\end{array}$ & $\begin{array}{c}17.1 \\
(N=36)\end{array}$ & $\begin{array}{c}27.8 \\
(N=35)\end{array}$ \\
\hline Massage chair & $\begin{array}{c}36.1 \\
(N=36)\end{array}$ & $\begin{array}{c}12.1 \\
(N=33)\end{array}$ & $\begin{array}{c}37.5 \\
(N=32)\end{array}$ \\
\hline Combined & 36.6 & 14.7 & 32.4 \\
\hline
\end{tabular}

NOTE.-Results reported are the choice shares of the perceptually focal option A relative to the asymmetrically dominating option $B$.

we first compared the relative choice share of $\mathrm{A}$ in the intuitive condition (perceptual problem task) to its share in the analytic condition (five-problem task). Consistent with our predictions, the data reveal that option A was more preferred following a perceptual task $(36.6 \%)$ than following five addition problems $(14.7 \%)$. Comparing the relative choice share of the perceptually focal option in the depletion condition (15-problem task) to its share in the analytic condition (five-problem task) reveals a similar pattern: option A was more preferred following 15 addition problems (32.4\%) than following five problems (14.7\%).

The significance of these results was tested using a logistic regression model in which choice is a function of the manipulation task and product category. The overall effect of priming task on preference was significant $\left(\chi^{2}(1)=8.77\right.$, $p<.05)$. Consistent with our predictions, we found that the preference for option A among participants using an intuitive mode of processing (perceptual problem task) was significantly higher than among participants using an analytic mode of processing (five-problem task; $\chi^{2}(1)=8.31, p<$ $.005)$. Likewise, we found that the preference for $\mathrm{A}$ was significantly lower among participants using an analytic mode of processing (five-problem task) than among participants who were depleted of resources (15-problem task; $\left.\chi^{2}(1)=5.77, p<.05\right)$. The effects of product category were nonsignificant $\left(\chi^{2}(1)<1\right)$ and did not interact with the experimental manipulation $\left(\chi^{2}(1)<1\right)$, suggesting that the results were consistent across categories.

\section{Discussion}

The results of experiment 4 further support the proposition that the influence of the perceptual characteristics of a set on choice is moderated by consumer mode of processing. Specifically, we found that a task performed before choice could influence subsequent preferences. Individuals who performed a perceptually oriented task prior to choice were more likely to prefer perceptually focal options than individuals who performed a short analytic task. Similarly, individuals who performed a longer, resource-depleting ana- 
lytic task prior to making a choice tended to prefer perceptually focal options more than individuals who had performed the short analytic task. By using a priming task to manipulate mode of processing, this study extends the results of the previous experiments by showing that preferences can be influenced by previous tasks designed to encourage analytic or intuitive processing.

\section{GENERAL DISCUSSION}

This research investigates a scenario in which irrelevant options influence choice by changing the perceptual characteristics of the decision set. Contrary to normative predictions, we find that adding fully dominated options can make one alternative perceptually focal and increase its likelihood of being chosen. A theoretical account for the data is based on dual-process theories of decision making, which posit that, in general, consumers can make choices using either more intuitive or more analytic processing. In particular, we found that consumers who make choices using more intuitive processing tend to prefer perceptually focal options while those using more analytic processing tend to prefer asymmetrically dominating options.

To examine how the visual characteristics of a decision set can influence choice, we contrasted the perceptual focus effect with the attraction effect. In this context, we found that the preference for asymmetrically dominating options decreased in the presence of a perceptually focal option. We further found that the attraction effect could be reversed when the perceptual characteristics of the set were changed by adding dominated options.

These findings contribute to the marketing literature on context effects in choice by empirically documenting the impact of perceptual context on choice. Previous research on context effects has illustrated the relational nature of preferences by demonstrating that an option can be more appealing in one set of options than in another (e.g., Huber et al. 1982). The literature on context effects in choice grew out of similar findings in the domain of perception (Wertheimer 1923/1999), showing that the visual context can influence perceptions of an object. For example, a circle will seem smaller when surrounded by large circles than when surrounded with small circles. The current research adds to the literature on context effects in choice by reemphasizing the importance of the visual context in choice. Although previous research has shown that adding options to a choice set can affect preferences by changing the comparisons consumers make between alternatives, the findings presented in this article demonstrate that the visual properties of the options themselves can also influence choice by drawing attention to one of the options in the set.

The research reported in this article presents a novel approach to investigating intransitive preferences in consumer choice. Intransitivity has typically been investigated by looking at how preference for options changes across choice contexts (Kivetz and Simonson 2000; Tversky 1969). In contrast, we extend the notion of preference transitivity to an attributespecific context and show that the presence of a perceptually salient option can lead to intransitive attribute preferences. These results may further indicate that mode of processing can affect the stability of consumer preferences. It is interesting to note that, although in any individual choice participants using intuitive processing were more likely to choose the perceptually focal option and participants using analytic processing were more likely to choose the asymmetrically dominating option, only those using intuitive processing formed intransitive attribute preferences across multiple choices. This may indicate that consumers who use an analytic mode of processing during choice form more stable preferences. Previous research has investigated factors such as experience and effort as moderators of the stability of consumer preferences (Hoeffler and Ariely 1999). The research presented in this article suggests that mode of processing can also have a significant impact on preference stability.

The findings of this research make an important contribution to our understanding of the mechanisms underlying the attraction effect. Previous research on the attraction effect has suggested that the effect is largely intuitive in nature. For example, Simonson (1989) found that, although asking participants to provide reasons for their choices increased the strength of the attraction effect, the reasons that participants actually gave for their choices rarely involved asymmetric dominance. It was argued that the attraction effect may be "perceptual" in nature-suggesting an intuitive process-and that reason-based processing may simply strengthen consumers' initial intuitive preferences. In the same vein, Pocheptsova et al. (2006) show that the strength of the attraction effect increases when participants are depleted of resources, making them more likely to rely on intuitive than analytical processing.

In contrast with the idea that the attraction effect is rooted in intuitive processes, the current research suggests that the attraction effect can be driven by analytic processes as well. In particular, we found that making an option perceptually focal was able to weaken or even reverse the preference for an asymmetrically dominating option. The idea that the attraction effect is an analytic (System 2) effect is strengthened by the fact that the preference for an asymmetrically dominating option increased when analytic processing was encouraged, both when analytic processing was encouraged by generating reasons for choice (experiments 1 and 3) and by doing mental arithmetic before making a choice (experiment 4). This view of the attraction effect is consistent with previous research (Ariely and Wallsten 1995; Prelec, Wernerfelt, and Zettelmeyer 1997; Simonson and Tversky 1992), which has invoked relatively analytic processes in explaining consumer preferences for an asymmetrically dominating option.

Taken together, research on the attraction effect suggests one of two intriguing possibilities. First, it could be that the attraction effect is driven by intuitive processes, which are strengthened by invoking analytic processes. Second, and perhaps more likely, it could be that the attraction effect is multiply determined. In other words, there might be both intuitive and analytic drivers of consumers' preference for an asym- 
metrically dominating option. This multiple-process model would help explain some of the effect's robustness in research. Unraveling and isolating the possible mechanisms of the attraction effect is a promising area for future research.

The research presented in this article has practical implications for manufacturers and retailers in determining the size and composition of their product assortments. In particular, when designing product displays in both print and electronic media, companies need to be aware of the potential impact of the visual characteristics of choice alternatives on consumer preferences. This becomes increasingly important with the current tendency to facilitate comparisons between products by using symbols such as figures, shapes, and numbers to position products. For example, Dell uses partially filled circle ratings to illustrate the relative benefits of its offerings, and Consumer Reports and C|NET use bar graphs to contrast different products and services, facilitating comparisons across brands. In this context, current research suggests that the way companies organize visual information could draw consumers' attention to a particular option, thereby increasing its choice share. By showing the impact of perceptual focus on consumer preferences, this research demonstrates that, in addition to the many overt ways in which companies can draw attention to products, the visual arrangement of alternatives can also have a significant influence on their relative choice shares.

\section{APPENDIX A}

TABLE A1

OVERVIEW OF THE STIMULI USED IN EXPERIMENT 1

\begin{tabular}{|c|c|c|c|c|c|}
\hline Product/attributes & $\begin{array}{c}\text { Option } \\
\text { A }\end{array}$ & $\begin{array}{c}\text { Option } \\
\text { B }\end{array}$ & $\begin{array}{c}\text { Option } \\
\text { C }\end{array}$ & $\begin{array}{c}\text { Option } \\
\text { D }\end{array}$ & $\begin{array}{c}\text { Option } \\
\text { E }\end{array}$ \\
\hline \multicolumn{6}{|l|}{ Sunglasses: } \\
\hline UV-A protection & 90 & 70 & 70 & 70 & 70 \\
\hline UV-B protection & 70 & 90 & 85 & 67 & 65 \\
\hline \multicolumn{6}{|l|}{ MP3 player: } \\
\hline Features & 80 & 60 & 60 & 60 & 60 \\
\hline Ease of use & 60 & 80 & 75 & 57 & 55 \\
\hline \multicolumn{6}{|l|}{ Sofa: } \\
\hline Spring durability & 60 & 80 & 75 & 57 & 55 \\
\hline Cushion softness & 80 & 60 & 60 & 60 & 60 \\
\hline \multicolumn{6}{|l|}{ Cell phone: } \\
\hline Durability & 50 & 70 & 65 & 47 & 45 \\
\hline Battery life & 70 & 50 & 50 & 50 & 50 \\
\hline
\end{tabular}

NOTE.-The order of the options in the experimental stimuli was varied by category, such that the core options A and B always appeared in one of the middle positions in the table. In addition, stimuli were counterbalanced so that, for some of the respondents, the perceptually focal option was $A$ and for the others the perceptually focal option was B. To illustrate, when choosing among MP3 players, the set AB [(80, 60); $(60,80)]$ remained the same for all participants, but for some respondents $A$ was made focal by adding $C_{1} D_{1} E_{1}[(60,75) ;(60,57) ;(60,55)]$ as shown above and for the others $B$ was made focal by adding $C_{2} D_{2} E_{2}[(75$, $60) ;(57,60) ;(55,60)]$. For clarity, the perceptually focal option is referred to as option A throughout this article.

\section{APPENDIX B}

TABLE B1

OVERVIEW OF THE STIMULI USED IN EXPERIMENT 2

\begin{tabular}{|c|c|c|c|c|c|}
\hline Product/attributes & $\begin{array}{c}\text { Option } \\
A\end{array}$ & $\begin{array}{c}\text { Option } \\
\mathrm{B}\end{array}$ & $\begin{array}{c}\text { Option } \\
\text { C }\end{array}$ & $\begin{array}{c}\text { Option } \\
\text { D }\end{array}$ & $\begin{array}{c}\text { Option } \\
\mathrm{E}\end{array}$ \\
\hline \multicolumn{6}{|l|}{ Light bulb: } \\
\hline Durability & $\odot$ & 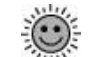 & $\odot$ & 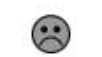 & 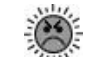 \\
\hline $\begin{array}{l}\text { Energy saving } \\
\text { Microwave: }\end{array}$ & 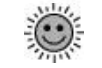 & $\odot$ & $\odot$ & $\odot$ & $\odot$ \\
\hline $\begin{array}{l}\text { Ease of use } \\
\text { Power } \\
\text { MP3 player: }\end{array}$ & $\begin{array}{l}80 \\
60\end{array}$ & $\begin{array}{l}60 \\
80\end{array}$ & $\begin{array}{l}74 \\
60\end{array}$ & $\begin{array}{l}56 \\
60\end{array}$ & $\begin{array}{l}55 \\
60\end{array}$ \\
\hline Memory & 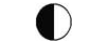 & & C & e & 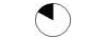 \\
\hline Ease of use & & & 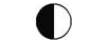 & 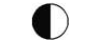 & \\
\hline
\end{tabular}


TABLE B1 (Continued)

\begin{tabular}{|c|c|c|c|c|c|}
\hline Product/attributes & $\begin{array}{c}\text { Option } \\
\text { A }\end{array}$ & $\begin{array}{c}\text { Option } \\
\text { B }\end{array}$ & $\begin{array}{c}\text { Option } \\
\text { C }\end{array}$ & $\begin{array}{c}\text { Option } \\
\text { D }\end{array}$ & $\frac{\text { Option }}{\mathrm{E}}$ \\
\hline \multicolumn{6}{|l|}{ Shirt: } \\
\hline Wrinkle-resistant & $\star \star$ & $\stackrel{\star \star \star}{\star \star \star}$ & $\star \star \star \star$ & $\star \star$ & $\star$ \\
\hline Stain-resistant & $\begin{array}{c}\star \star \star \\
\star \star \star\end{array}$ & $\star \star$ & $\star \star$ & $\star \star$ & $\star \star$ \\
\hline
\end{tabular}

NOTE.-Participants in the three-option conditions saw only options A, B, and C. When choosing from the light bulb and MP3 player categories, participants were given a key showing the full range of the smiley-face and circle scales, respectively. In the experimental stimuli, the smiley faces were colored: the two "positive" faces were green, the "neutral" face was yellow, and the two "negative" faces were red. The order of the options in the experimental stimuli was varied by category, such that, in the five-option sets, options $A$ and $B$ always appeared in one of the middle positions in the table.

\section{APPENDIX C}

\section{TABLE C1}

OVERVIEW OF THE STIMULI USED IN EXPERIMENT 3

\begin{tabular}{|c|c|c|c|c|c|}
\hline Product/set/attributes & $\begin{array}{c}\text { Option } \\
\text { A }\end{array}$ & $\begin{array}{c}\text { Option } \\
\text { B }\end{array}$ & $\begin{array}{l}\text { Option } \\
\text { C }\end{array}$ & $\begin{array}{l}\text { Option } \\
\text { D }\end{array}$ & $\begin{array}{c}\text { Option } \\
\mathrm{E}\end{array}$ \\
\hline \multicolumn{6}{|l|}{ Vitamin water: } \\
\hline \multicolumn{6}{|l|}{ Set 1: } \\
\hline Endurance & 60 & 80 & 74 & 56 & 55 \\
\hline Energy & 80 & 60 & 60 & 60 & 60 \\
\hline \multicolumn{6}{|l|}{ Set 2: } \\
\hline Energy & 60 & 80 & 74 & 56 & 55 \\
\hline Stress relief & 80 & 60 & 60 & 60 & 60 \\
\hline \multicolumn{6}{|l|}{ Set 3: } \\
\hline Stress relief & 60 & 80 & 74 & 56 & 55 \\
\hline Endurance & 80 & 60 & 60 & 60 & 60 \\
\hline \multicolumn{6}{|l|}{ Digital camera: } \\
\hline \multicolumn{6}{|l|}{ Set 1: } \\
\hline Features & 90 & 70 & 70 & 70 & 70 \\
\hline Resolution & 70 & 90 & 84 & 66 & 65 \\
\hline \multicolumn{6}{|l|}{ Set 2: } \\
\hline Resolution & 90 & 70 & 70 & 70 & 70 \\
\hline Memory & 70 & 90 & 84 & 66 & 65 \\
\hline \multicolumn{6}{|l|}{ Set 3: } \\
\hline Memory & 90 & 70 & 70 & 70 & 70 \\
\hline Features & 70 & 90 & 84 & 66 & 65 \\
\hline
\end{tabular}

NoTE.-Participants chose from all three sets in each product category. The order in which the sets were presented was counterbalanced across participants. The order of the options in the experimental stimuli was varied by category, such that in the five-option sets options A and B always appeared in one of the middle positions in the table.

\section{REFERENCES}

Ariely, Dan and Thomas S. Wallsten (1995), "Seeking Subjective Dominance in Multidimensional Space: An Explanation of the Asymmetric Dominance Effect," Organizational Behavior and Human Decision Processes, 63 (September), 223-32.

Baumeister, Roy F., Ellen Bratslavsky, Mark Muraven, and Dianne Tice (1998), "Ego Depletion: Is the Active Self a Limited Resource?" Journal of Personality and Social Psychology, 74 (May), 1252-65.

Baylis, Gordon C. and Jon Driver (1992), "Visual Parsing and Response Competition: The Effect of Grouping Factors," Perception and Psychophysics, 51 (February), 145-62.

Bettman, James R., Mary Frances Luce, and John W. Payne (1998), "Constructive Consumer Choice Processes," Journal of Consumer Research, 25 (December), 187-217.

Bradley, Drake R. and Heywood M. Petry (1977), "Organizational
Determinants of Subjective Contour: The Subjective Necker Cube," American Journal of Psychology, 90 (June), 253-62. Chernev, Alexander (2005a), "Context Effects without a Context: Attribute Balance as a Reason for Choice," Journal of Consumer Research, 32 (September), 213-23.

- (2005b), "Feature Complementarity and Assortment in Choice," Journal of Consumer Research, 31 (March), 748-59.

Dhar, Ravi and Stephan M. Nowlis (1999), "The Effect of Time Pressure on Consumer Choice Deferral," Journal of Consumer Research, 25 (March), 369-84.

Dhar, Ravi and Itamar Simonson (1992), "The Effect of the Focus of Comparison on Consumer Preferences," Journal of Marketing Research, 29 (November), 430-40.

Duncan, John and Glyn W. Humphreys (1989), "Visual Search and Stimulus Similarity," Psychological Review, 96 (July), 433-58.

Epstein, Seymour, Abigail Lipson, Carolyn Holstein, and Eileen 
Huh (1992), "Irrational Reactions to Negative Outcomes: Evidence for Two Conceptual Systems," Journal of Personality and Social Psychology, 62 (February), 328-39.

Garbarino, Ellen C. and Julie A. Edell (1997), "Cognitive Effort, Affect, and Choice," Journal of Consumer Research, 24 (September), 147-58.

Hoeffler, Steve and Dan Ariely (1999), "Constructing Stable Preferences: A Look into Dimensions of Experience and Their Impact on Preference Stability," Journal of Consumer Psychology, 8 (2), 113-39.

Hogarth, Robin M. (2001), Educating Intuition, Chicago: University of Chicago Press.

Huber, Joel, John W. Payne, and Christopher Puto (1982), “Adding Asymmetrically Dominated Alternatives: Violations of Regularity and the Similarity Hypothesis," Journal of Consumer Research, 9 (June), 90-98.

Huber, Joel and Christopher Puto (1983), "Market Boundaries and Product Choice: Illustrating Attraction and Substitution Effects," Journal of Consumer Research, 10 (June), 31-44.

Kahneman, Daniel (1973), Attention and Effort, Englewood Cliffs, NJ: Prentice-Hall.

(2003), "Maps of Bounded Rationality: Psychology for Behavioral Economics," American Economic Review, 93 (December), 1449-75.

Kahneman, Daniel and Shane Frederick (2002), "Representativeness Revisited: Attribute Substitution in Intuitive Judgment," in The Psychology of Intuitive Judgment: Heuristics and Biases, ed. Thomas Gilovich, Dale Griffin, and Daniel Kahneman, New York: Cambridge University Press.

Kivetz, Ran and Itamar Simonson (2000), “The Effects of Incomplete Information on Consumer Choice," Journal of Marketing Research, 37 (November), 427-48.

Lurie, Nicholas H. (2004), "Decision Making in Information-Rich Environments: The Role of Information Structure," Journal of Consumer Research, 30 (March), 473-86.

Payne, John W. (1982), "Contingent Decision Behavior," Psychological Bulletin, 92 (2), 382-402.

Payne, John W., James R. Bettman, and Mary Frances Luce (1996), "When Time Is Money: Decision Behavior under Opportunity-Cost Time Pressure," Organizational Behavior and $\mathrm{Hu}$ man Decision Processes, 66 (2), 131-52.
Pocheptsova, Anastasiya, On Amir, Ravi Dhar, and Roy Baumeister (2006), "Deciding without Resources: Psychological Depletion and Choice in Context," working paper, School of Management, Yale University, 135 Prospect Street, New Haven, CT 06511.

Prelec, Drazen, Birger Wernerfelt, and Florian Zettelmeyer (1997), "The Role of Inference in Context Effects: Inferring What You Want from What Is Available," Journal of Consumer Research, 24 (June), 118-25.

Quinlan, Philip T. and Richard N. Wilton (1998), "Grouping by Proximity or Similarity? Competition between the Gestalt Principles in Vision," Perception, 27 (4), 417-30.

Simonson, Itamar (1989), "Choice Based on Reasons: The Case of Attraction and Compromise Effects," Journal of Consumer Research, 16 (September), 158-74.

Simonson, Itamar and Stephen M. Nowlis (2000), "The Role of Explanations and Need for Uniqueness in Consumer Decision Making: Unconventional Choices Based on Reasons," Journal of Consumer Research, 27 (June), 49-68.

Simonson, Itamar and Amos Tversky (1992), "Choice in Context: Tradeoff Contrast and Extremeness Aversion," Journal of Marketing Research, 29 (August), 281-95.

Sloman, Steven A. (1996), "The Empirical Case for Two Systems of Reasoning," Psychological Bulletin, 119 (January), 3-22.

Treisman, Anne M. and Garry Gelade (1980), "A Feature-Integration Theory of Attention," Cognitive Psychology, 12 (1), 97-136.

Tversky, Amos (1969), "Intransitivity of Preferences," Psychological Review, 76 (January), 31-48.

- (1977), "Features of Similarity," Psychological Review, 84 (October), 327-52.

Vohs, Kathleen, Roy F. Baumeister, Jean Twenge, Brandon Schmeichel, and Dianne Tice (2006), "Decision Fatigue Exhausts Self-Regulatory Resources," working paper, Carlson School of Management, University of Minnesota, 321 Nineteenth Avenue South, Minneapolis, MN 55455.

Wertheimer, Max (1923/1999), "Laws of Organization in Perceptual Forms," in A Source Book of Gestalt Psychology, ed. W. D. Ellis, New York: Routledge, 71-88; reprinted from Max Wertheimer (1923), Psychologische Forschung, 4, 301-50. 
Copyright of Journal of Consumer Research is the property of Journal of Consumer Research. Inc. and its content may not be copied or emailed to multiple sites or posted to a listserv without the copyright holder's express written permission. However, users may print, download, or email articles for individual use. 